\title{
AIRBORNE LIDAR FOR NATURAL ENVIRONMENTS: RESEARCH AND APPLICATIONS IN FRANCE
}

\author{
Christian Puech ${ }^{1}$, Sylvie Durrieu ${ }^{1}$, Jean-Stéphane Bailly $^{2}$ \\ 1: IRSTEA, UMR TETIS, $34093 \quad$ Montpellier - France puech@teledetection.fr; \\ sylvie.durrieu@teledetection.fr \\ 2: AgroParisTech, UMRs TETIS et LISAH, 34093 Montpellier - FRANCE \\ bailly@teledetection.fr
}

\section{Introduction}

Natural environments can be defined as areas with low anthropogenic pressure. They do not include urban areas and any other area highly impacted by human activity such as intensive agriculture or industrial areas. They often include forested and mountainous areas as well as alluvial plains. In metropolitan France, natural environments (i.e. moors, waste lands, shrublands, forests, permanent grasslands) account for about $54 \%$ of the total surface area (MAAPAR, 2011). This percentage is even higher in some Overseas Departments and Regions. In French Guyana, for example, tropical forests cover up to $96 \%$ of the surface area. Although pioneering works on pulsed-light cloud-heigh detectors were developed in France by Barthelémy and Bureau in 1935 (Flamant, 2005), the development of research work using airborne "Light detection and ranging", i.e. LiDAR, for the monitoring and management of natural environ- ment only started in the early 2000's. In 2002, only five airborne LiDAR experiments were registered over the French metropolitan territory. Ten years later, it is almost inconceivable to accurately list all airborne LiDAR surveys. The IGN (the French National Institute for Geographic and Forest Information) is now equipped with an airborne LiDAR for large extent topographic surveys. For instance, we can mention the Litto3D program from both the SHOM (The French Naval Hydrographic and Oceanographic Service) and the IGN which was initiated in 2007: this program aims at acquiring a $1 \mathrm{~m} \mathrm{DTM}$ with decimeter accuracy for all French coastal areas (Flamanc and Le Roux, 2007) using both the topographic system owned by the IGN and bathymetric systems flown by data providers.

However, after 10 years of research and studies on airborne LiDAR in France, what is the state of the art on research for natural environments observation? And what 
new scientific questions have arisen from the use of airborne LiDAR data?

This paper gives an overview of the different research works focused on airborne LiDAR, also called airborne laser scanner (ALS), for studies on natural environment in France. It is partly based on the analysis of published texts through two seminars on LiDAR, the first in Montpellier in 2006 (http://LiDAR.teledetection.fr/, RFPT issue 186) and the other one in Le Mans in 2009 (RFPT issues 191 and 192). Moreover, this review is complemented by the results of more recent research. It appears that the development of methods using airborne LiDAR data is now encountered in most areas having environmental or mapping issues. The technology has several features that can explain its relevance in these areas, while at the same time limiting its scope of employment:

- The possibility of obtaining data describing surface composition above the ground.

-Access to ground elevation data under vegetation.

-Simultaneous access to elevation from the top of the canopy, allowing a measure of vegetation height.

-Capacity of measuring elements of a few decimeters in size, or even less in some applications.

-The flexibility of obtaining very high resolution data.

-Although still onerous, costs have significantly fallen and for certain applications have become lower than field experiment expenses, especially in hilly areas.

-An acquisition mode that is suited to linear elements of the landscape along a flight line for rivers, riparian forests, roads, coastal lines, etc but also to surface mapping.

This paper focus on LiDAR thematic applications dealing with forestry and hydrological issues, in addition other works related, for example, to forest archaeology or ecosystems monitoring.

In this paper we only present techniques used to analyze data acquired with laser range finders. The backscattered signal gives access 1) to the ground position, providing the DTM (Digital Terrain Model); 2) to the top position, i.e. forest canopy or roofs, providing the numerical model of surface DSM, (Digital Surface Model); 3) to their difference, i.e. the height of the above ground features, providing the CHM (Canopy Height Model, Figure 4); 4) to the intermediate structure of the observed features by analysing either the complete backscattered waveform or more partial information extracted between the beginning and the end of the backscattered signal; and 5) to the bathymetry in the case of rivers or water bodies.
After a brief overview of LiDAR data theory and practices, we present a review of thematic studies and applications. We thereafter provide a summary of research work undertaken to improve elevation LiDAR accuracy, such as filtering methods and their impact on product quality. Finally we focus on new systems developments and on space application perspectives.

\section{LiDAR data}

LiDAR acquisition is based on the emission and reception of a laser beam. The time of flight of the light emitted informs on the distance between the LiDAR system, made up of transmitter, receiver and detector systems, and the target. For an airborne LiDAR system, the sensor position and the viewing angle are assessed by coupling a DGPS system and an inertial system that allows to estimate the XYZ coordinates of the target.

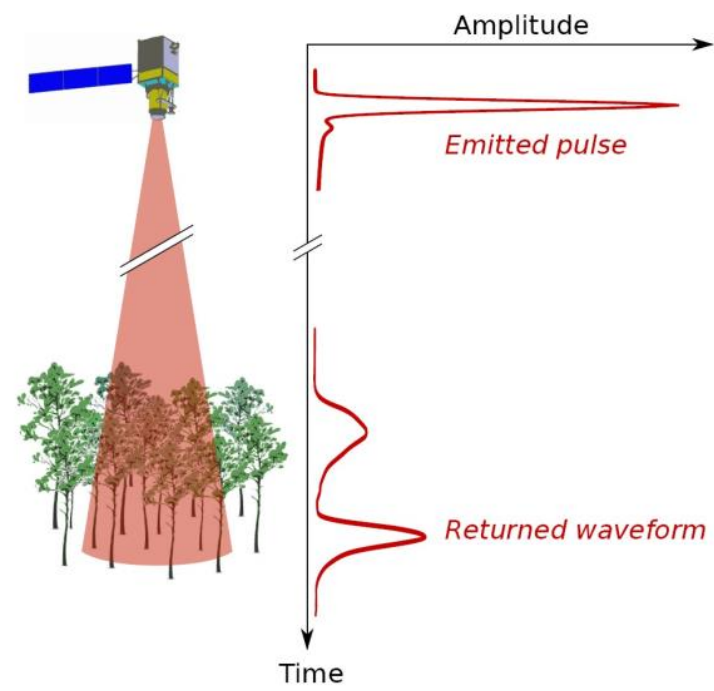

Figure 1: The Principle of LiDAR measurement: an echo is backscattered toward the sensor every time the laser beam is partially or totally intercepted by an obstacle (Figure by T. Allouis, in (Durrieu, 2010).

When emitted pulse length is short, i.e. a few nanoseconds, the backscattered signal forming a wave consists in a succession of echoes corresponding to any obstacle encountoured by laser beam (Figure 1). The distance between the LiDAR system and encountoured targets is derived from this waveform. It can be analyzed and stored in a single echo mode, i.e. when only first or last echoes are stored, in a first and last echo mode, in a multi-echo mode, i.e. when intermediate echoes are registered, or can be digitized with a very high temporal frequency (typically every nanosecond) giving access to the "full waveform" backscattered by the target (Figure 2). As a result, the geometric position of the target are usually interpolated in raster models (Figure 3). Ultimate altimetric accuracy depends on three stages: 1) detection of distances between the LiDAR system and the target for 


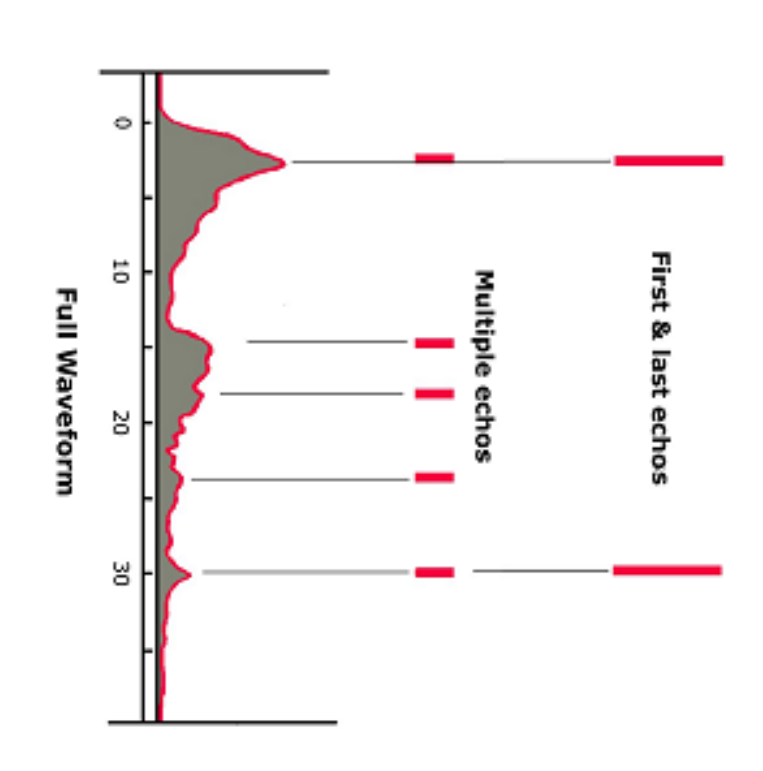

Figure 2 : The most common modes of LiDAR acquisitions.

each emitted LiDAR pulse; 2) classification (or filtering) to separate ground echoes from above ground echoes; 3 ) horizontal interpolation to generate surface models, most often in raster format.

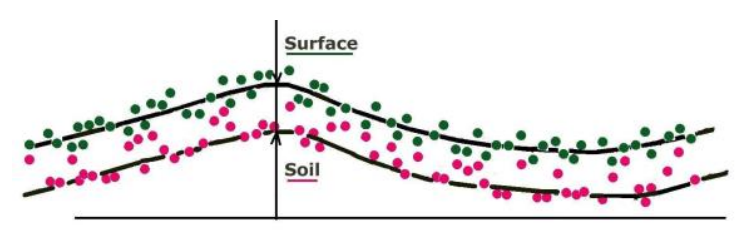

Figure 3 : Example of horizontal interpolation Green points for first echoes and red points for last echoes. Last echoes are filtered before interpolation.

Data acquired with LiDAR recording either both first and last echoes or multi-echoes are the most commonly used. The first echo is supposed to be generated by the topmost features while the last one, by the ground. Generally, the two corresponding point sub-clouds, are resampled using a raster mesh, for example with $1 \mathrm{~m} \times 1 \mathrm{~m}$ pixels, providing both DSM and DTM respectively. Their difference gives the height of representative features, e.g. the CHM, in the case of a forest.

These three surfaces are now commonly used in many applications. They provide very useful data to different applications, and satisfy standard accuracy requirements.

With a multi echo system, up to 7-8 echoes can be detected over forest environments. The intermediate echoes can provide invaluable knowledge on the different features above the ground: herbs, shrubs, trees and elements of the canopy.

Finally, the "full waveform" systems gives access to the whole backscattered signal. This enables the detec-

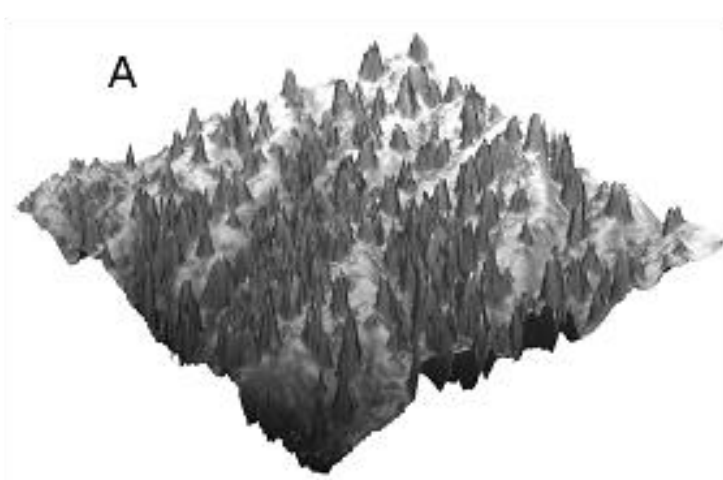

Digital Surface Model

B

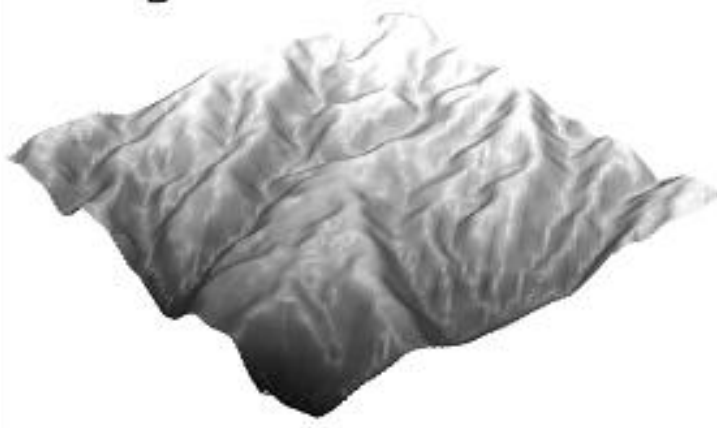

- Digital Terrain Model

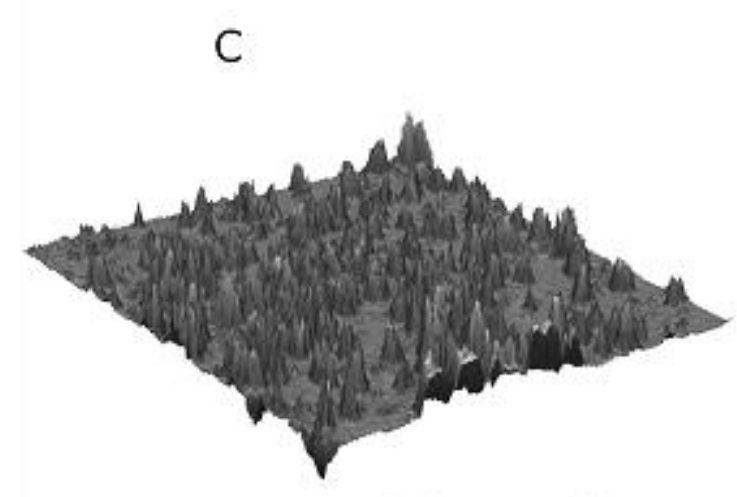

$=$ Canopy Height Model

Figure 4 : CHM (C) computed as the difference between the DSM (A) and the DTM (B) (from Bailly et al. (2012)). 
tion of much finer data on the cover structure, but leads to voluminous data, which generate storage and processing challenges. Some studies aims to retrieve from waveforms parameters of intermediate strata such as forest transparency or water column turbidity in water column Another issue is to increase or to estimate LiDAR data accuracy. In this case, analysis focuses on what LiDAR echoes actually represent. This paper does not discuss the uncertainties linked to vector geo-referencing in flight, but instead deals with the consequences of the complex interactions between the emitted pulse and the targets on the signal and the its processing.

\section{Thematic applications based on LiDAR raster DTMs}

Without being truly exhaustive, this review strives to illustrate the enthusiasm and creativity in the uses of these new technologies in research for the various themes relating to natural environment management.

Most of the operational or semi operational applications presented here use LiDAR data provided by specialized private companies. Basically, used LiDAR data are DTM and DSM. These layers are generally provided in raster mode which facilitates coupling and analysis with traditional data and their integration into models. However some applications use "point cloud" data. Only a few specific applications use bathymetric LiDAR data which comes from a dual laser emission system, both in green and near-infrared bands, in order to separate the water surface echo from the bottom echo. Most of publications focus on the use of these raster data, as new valuable data, and are generally perceived as innovative. In particular they address certain limits of other methods. LiDAR data provide an accurate topography of either surface or ground over environments where traditional digital photogrammetry does not perform well. For instance, in cas of poor correlation between images using stereo pairs or for topography under forest cover. They also provide an easy access to rugged areas and can be used to cover large surface areas at a lower cost where usual ground survey is too difficult. LiDAR data hence provide new research opportunities in many fields such as forest management, hydrology, hydraulics, geomorphology, archaeology and ecosystem monitoring.

\subsection{Forest mapping and management}

Forest managers need to know both the composition (tree species) and the structure of forest stands to assess forest resources and better understand forest ecosystem dynamics in order to manage resources in accordance with good sustainability practices. Based on tree structure measurements, biophysical indicators (such as timber volume or above ground biomass) can be derived from allometric relationships. Structural information, such as total tree height, stemwood height (trunk height up to a given diameter, usually $7 \mathrm{~cm}$ in France), and trunk diameter at $1 \mathrm{~m} 30$ are crucial in forestry and resource inventories are based on this data. This information are traditionally obtained through field measurements performed on forest plot samples. Sometimes, these measurements are made at the management units scale. However, these field measurements are not sufficient for structural descriptions required to calculate timber volumes and above ground biomass in a comprehensive manner over an extensive land or territory.

Airborne LiDAR, which can be used for geometric measurements of forest canopies over vast areas, opens numerous perspectives for the study and management of such ecosystems. CHM only provides a description of the topmost area of forest canopy. CHM can be used to extract the location and height of trees. Dorren et al. (2007) developed two methods based on the detection of local maxima in windows which sizes were determined by the height of the central pixel, thereby reducing the risk of detecting several maxima in the same crown. In softwood stands located in mountainous regions, they obtained a $10 \%$ error rate for the total number of dominant or co-dominant trees. The application of segmentation methods on CHM was used to delimit tree crowns when LiDAR measurement density was sufficient, i.e. several points per crown. Several segmentation approaches were developed to perform this segmentation. They are based on algorithms used to establish watershed boundaries applied on reverse CHM (Mei and Durrieu, 2004), on local geometric properties of CHM that can be used to rebuild crowns based on local maxima (Vega et al., 2011) (Figure 2), or alternatively on the fitting of simplified tree models based on marked point processes (Zhou et al., 2011). From the obtained segments, the total height and diameter of the crown can be extracted for each tree.

Crown diameter, which is correlated with trunk diameter, complements height information, and can be used to significantly improve statistical models for prediction of timber volumes and above ground biomass (Allouis et al., 2011a). However, these methods, which are used to detect tree locations and to segment tree crowns, do not provide consistent results in all types of forests, especially in very dense forest stands. (Véga et Durrieu, 2011) or when trees have collective formations, such as in the case of forests used for protection purposes (Dorren et al., 2007). Therefore, individual tree identification on an $\mathrm{CHM}$ can become problematic. Moreover, approaches at tree level require relatively high LiDAR measurement densities, which can lead to very prohibitive acquisition costs for vast area studies.

One alternative is to apply surface-based methods to characterize forest stands at the plot scale. Bock et al. (2011) were thus able to demonstrate that within circular plots (13.1 m radius), the heights of 5 points corresponding to the highest local maxima inside the plot, gave a robust estimation of the dominant height 


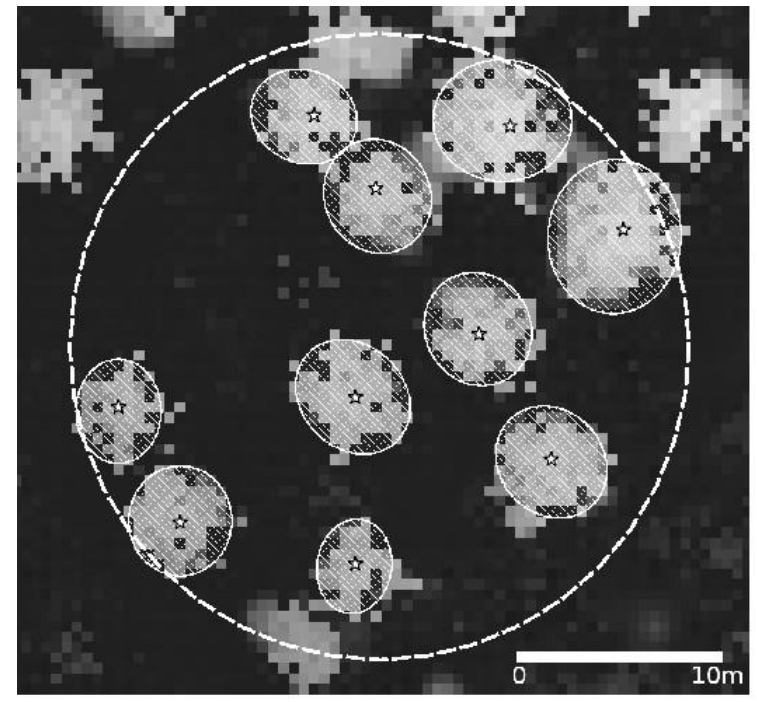

Figure 5: Tree crown segmentation within a $15 \mathrm{~m}$ radius plot (dashed) using the method proposed in Véga and Durrieu (2011). Tree crowns are modelled as ellipsoids (shaded ellipses).Tree heights (stars) are given by the maximum height within each crown.

(RMSE $=0.89 \mathrm{~m}, \mathrm{R}^{2}=0.99$ ) in heterogeneous hardwood stands. The 5 points were selected based on both height criteria (points from among the highest detected on the plot) and distances (points sufficiently far from the others). Dominant height can be retrieved by several approaches based on LiDAR derived metrics (Bock et al., 2009) using LiDAR data. This forest variable is of interest to forest managers as they often initiate silvicultural operations based on its value.

CHM LiDAR is also central to studies aiming to better characterize complex structures of tropical forest and to map forest types. Vincent et al. (2010) have therefore used local statistics describing CHM height distribution (e.g. median and mean height, standard deviation of heights, height percentiles...) combined with indicators derived from the DTM to characterize square plots of areas ranging from $30 \mathrm{~m} \times 30 \mathrm{~m}$ to $250 \mathrm{~m} \times 250 \mathrm{~m}$. The authors demonstrated that this information was as robust as field measurements to characterize different tropical forest types. Classification by discriminant analysis led to good classification rates of $80 \%$ when the forest was classed into 10 types at the highest resolution level $(5 \mathrm{~m})$ and of $87 \%$ when 6 forest type classes were considered for lower resolution analysis.

Another pioneering study used a LiDAR CHM to assess changes in texture generated by changes in acquisition configurations, i.e. sun height and viewing angle, and to analyse the sensitivity of the FOTO method (Fourier Transform Textural Ordination (Couteron et al., 2005)) to the changes in observation conditions (Barbier et al., 2011). The FOTO method can indeed be used to estimate different forest structures in tropical environments from very high resolution optical images. This method has also been directly applied to a LiDAR CHM in order to assess its potential to characterize the different stages of mangrove development (Proisy et al., 2009). Dupuy et al. (2011) have also highlighted the pertinence of coupling a LiDAR CHM to optical data at medium and high resolutions to map the main forest types on the island of Mayotte.

\subsection{Hydrology and Hydraulics}

Airborne LiDAR DTMs with metric resolution have been used in France for hydrology in two different contexts: i) for hillslope hydrology, and ii) for fluvial hydraulics.

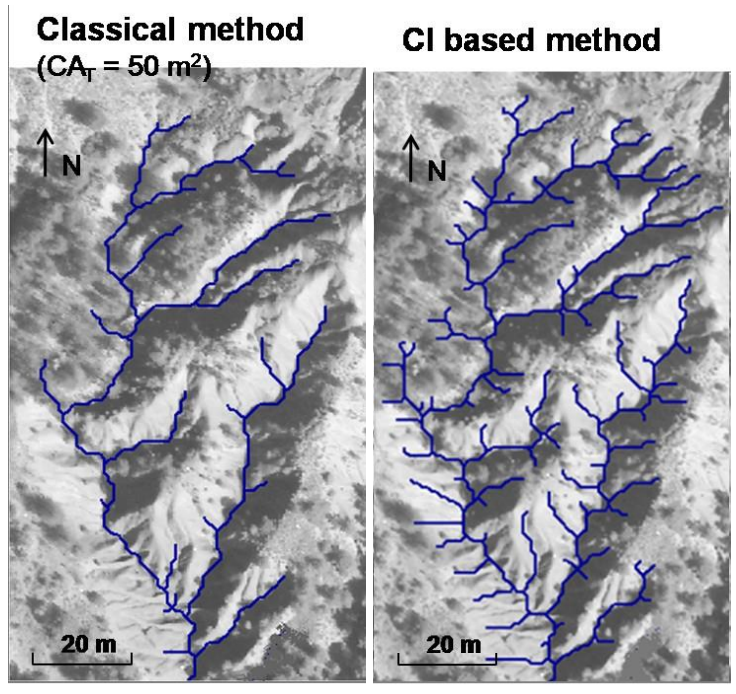

Figure 6: Comparison of thalweg networks (blue) extracted from $1 \mathrm{~m}$ LiDAR DTM on the Moulin-Draix catchment (Thommeret et al., 2011).

For hillslope hydrology, LiDAR DTMs was expected to better model rain transformation into flows or erosion through a better delineation of water paths over upstream surfaces. This was investigated in semi-artificial (intensively cultivated or peri-urban) head catchments (Bailly et al., 2008; Sarrazin, 2012) or mountainous head catchments (Thommeret et al., 2011).

Studies showed that drainage schemes obtained from LiDAR DTMs better take into account some anthropogenic elements and settlements (roads, ways, wide ditches) that govern water flow pathes but not for all linear elements, such as ditches of cultivated areas, for which Bailly et al. (2008) showed that only $60 \%$ are correctly detected. In mountainous and eroded areas, Thommeret et al. (2011) showed that thanks to a new drainage network extraction method (Figure 6), metric LiDAR DTMs allows the detection of gullies in badlands with a $90 \%$ accuracy. Other hydrological studies too advantage in a more straightforward manner from the high resolution and accuracy of LiDAR DTM. For instance, this was the case for the land soil long-term 


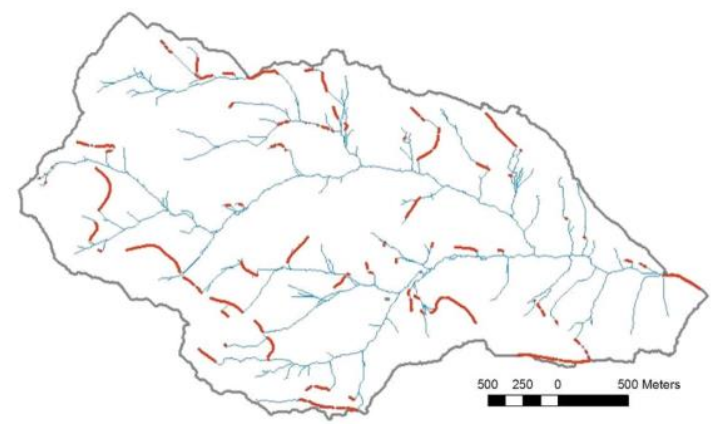

Figure 7 : Anthropogenic linear elements (red) of the hydrographic network delineated from a $1 \mathrm{~m}$ LiDAR DTM on the Mercier Catchment-Rhône (Sarrazin, 2012).

erosion model that simulates cultivated landscape evolution related to soil redistribution at a hillslope scale Ciampalini et al. (2012).

High spatial resolution and accurate topography is required to assess and prevent flood risk. Once again, the LiDAR DTM over large areas enables better hydrological processes modelling and better prediction of water flows: LiDAR DTMs, by identifying anthropogenic surface discontinuities such as roads, large ditches, etc improves water-path delineations (Figure 7), water transfer characterization and hydrographs (Sarrazin, 2012).

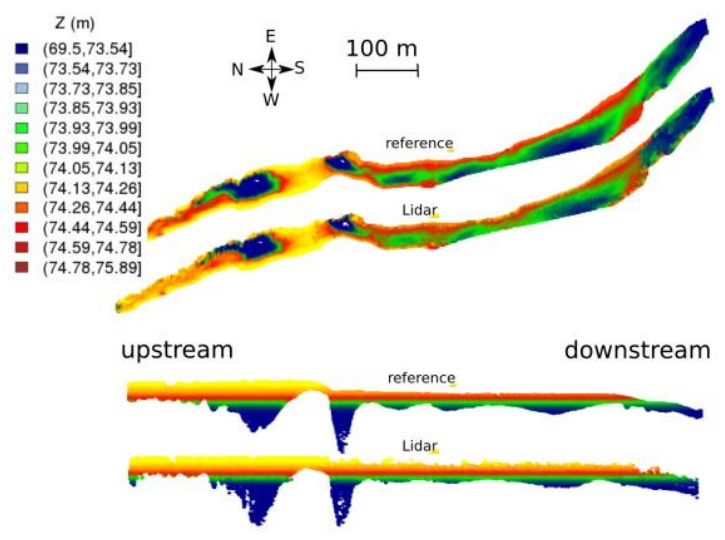

Figure 8: A riverbed DTM obtained from the Hawkeye green LiDAR on the Gardon river (Bailly et al., 2010) in comparison with ground truth DTM.

Airborne LiDAR data also are used as topographic inputs for flood plain hydraulic models or to produce water depths map substracting DTM to simulated water height. Papers devoted to this topic report on 1) the LiDAR ability to define water bodies and water storage capacities within floodplains, and the cost effectiveness of riverbed geometry survey when data acquisition is performed during dry seasons. Moreover airborne LiDAR data in floodplains can help to settle embankments, dams, etc, in order to prevent flood risk (Kreis et al., 2010).

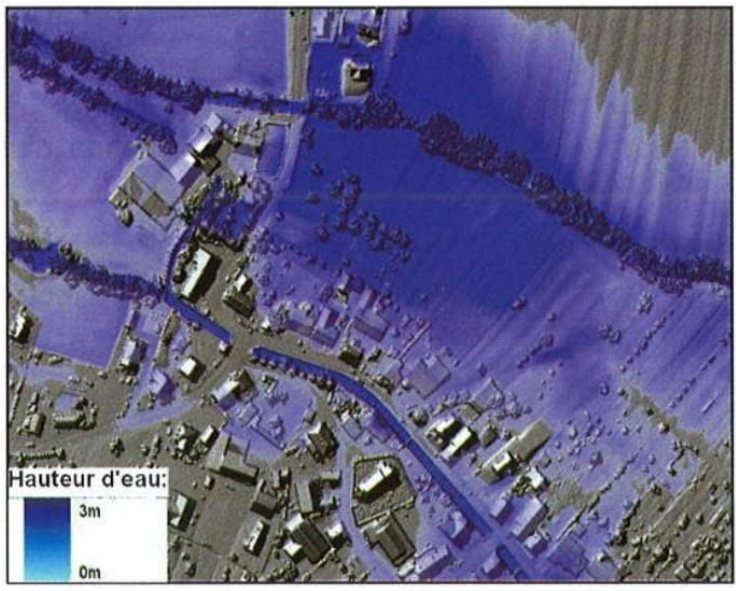

Figure 9 : Water in a flooded plain in the Haut-Rhin department (Kreis et al., 2010).

\subsection{Geomorphological monitoring of non- accessible surfaces}

Another advantage of airborne LiDAR is its ability to accurately measure and monitor terrain topography in areas affected by active geomorphological processes: glaciers, volcanoes, rifts, mountain streams, etc and where access is difficult or dangerous, which therefore limits the practicability of topographic field surveys.

As in the case of flood risk modelling, hillslope erosion modelling is an important topic with considerable economical impacts (dam siltation, etc). Improving erosion modelling is related to the improvement of hillslope hydrological modelling that is itself dependent on eroded relief modelling. LiDAR DTMs on eroded areas, e.g. badlands, are thus of great interest. With LiDAR, relief of areas with high slopes can be mapped with decimetric elevation accuracy (Panissod et al., 2010) and erosion gullies can be used as features to define the topology for hydrological models (Jacome, 2009).

A second advantage of LiDAR data for erosion assessment would be to monitor erosion processes over surfaces and time by measuring and locating the thickness and volume of deposital and eroded areas after geomorphological rainy events. However concerning elevation accuracy $(10-20 \mathrm{~cm})$ and erosion processes velocity (around $0.8 \mathrm{~cm} /$ year on badlands), airborne LiDAR is not suitable for short term monitoring. Up to now, only terrestrial LiDAR meets requirements in this context. LiDAR has been used for other natural hazard or geomorphological process monitoring or modelling. For instance, (Elineau et al., 2010) studied cliff collapse near Le Havre, France due to coastline modifications measured from two successive (1 year) DTMs. Their work aims to quantify the lost volumes accumulated at the bottom of the cliff to assess the rate of erosion in this area.

Another example comes from the monitoring of mountain 
glaciers. They are very sensitive to climate fluctuations and their monitoring provides good indicators of climate change allowing our knowledge improvement on environmental consequences. In particular, the glacier mass balance, which, up until now, was computed from diachronic DSMs obtained by photogrammetry (Berthier, 2007; Berthier and Vincent, 2012) allows us to assess the health status of the glacier and its relation to climate (Berthier and Vincent, 2012). However, Friedt et al. (2012) have recently demonstrated the value of LiDAR to generate accurate enough DSMs to achieve mass balance at a few year time step. Other geomorphological examples come from Earth crust deformations or active volcanic area monitoring, e.g. the Piton de la Fournaise Reunion island, using both LiDAR and radar interferometry in order to estimate the risk associated with volcanic eruptions (Heggy et al., 2010).

Finally, near-infrared LiDAR also proved to be efficient to map and monitor potential changes in a mountain river stream. Thanks to a specific LiDAR DTM segmentation process, Penard and Morel (2012) accurately and efficiently delineated wetted part of the stream from gravel banks (Figure 9).
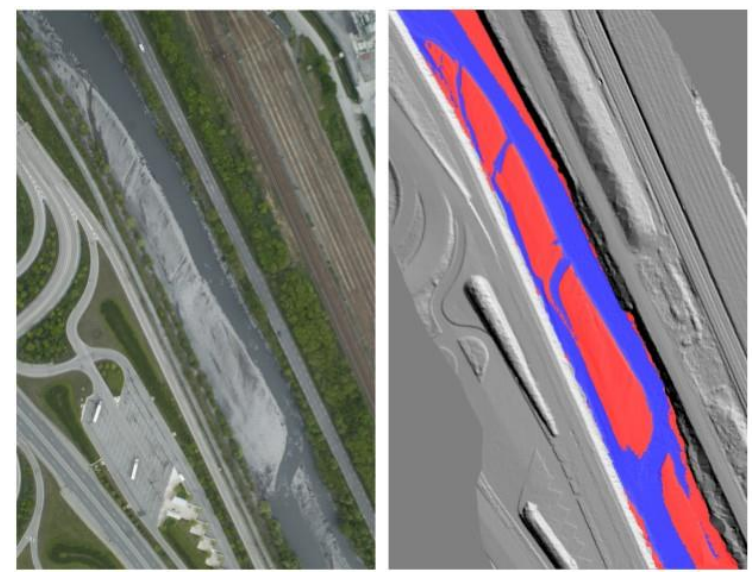

Figure 10 : Aerial photograph (left) and automated LiDAR DTM segmentation (right) of the Arc-en-Maurienne riverbed (blue : wetted river bed- red : gravels banks) from an automatic process proposed by Penard and Morel (2012).

\subsection{Structures and infrastructures detected from Li-} DAR data : from ancient past to present

Aerial archaeology has also progressed thanks the LiDAR data. It is essentially due the capacity to see under forest cover and to easily map some areas of difficult access using non-intrusive methods. Sittler and Koupaliantz (2007) show convincing examples of detection of historical paleo structures under forest cover in Alsace in sites where faint human traces are almost invisible from the ground (Figure 11). The DTM $1 \mathrm{~m} \times$ $1 \mathrm{~m}$ in raster format appears accurate enough to allow the detection of small-scale relief heterogeneity. The forest recolonization of once cultivated areas became, over time, vegetal screen hiding the ground and also providing protection for ancient structures. Thanks to LiDAR capabilities the vegetal screen becomes transparent. In the Haye forest in Lorraine, a site renowned for its GalloRoman traces, LiDAR acquisition in 2007 revealed the existence of archaeological remains of a structure that had been hidden until then (Bock et al., 2008). An intense mapping of archaeological sites was performed on this forest area.

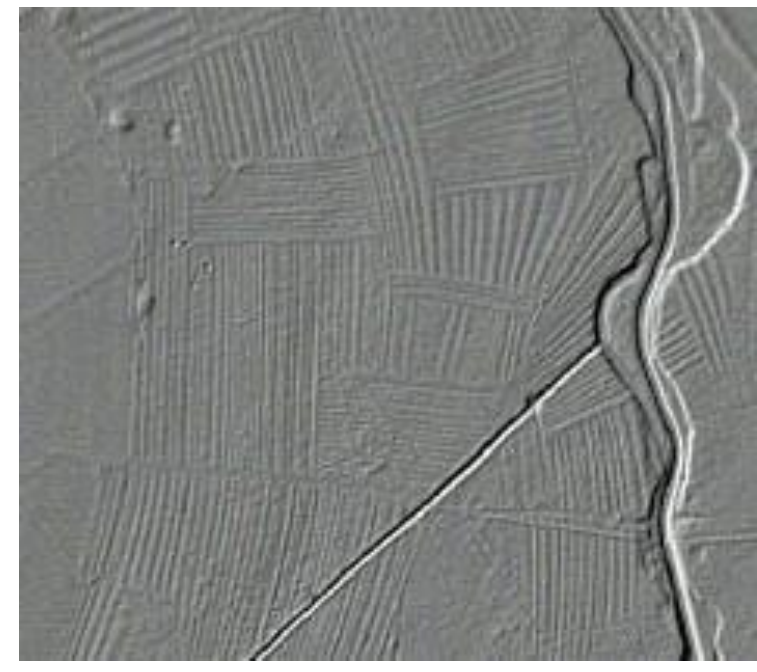

Figure 11 : LiDAR and traces under forest: fragmented medieval fields revealed by the latest laser echoes (Sittler and Koupaliantz, 2007).

LiDAR data also suited the study of linear structures and infrastructure such as electrical networks, railways, roads and rivers. For example, the mapping of ancient dikes was performed along the Rhône River. The "flipmap" project focused on several challenges: systematic dike mapping for technical inventory providing accurate plans of these ancient dikes (Clement and Mériaux, 186); for dykes covered by parasitic vegetation, vegetation mapping for rehabilitation work (Vennetier et al., 2010). These studies are conducted from data acquired from a helicopter with a very high density of points, 120 $\mathrm{pts} / \mathrm{m}^{2}$.

\subsection{Coastal ecosystems monitoring and coastal zone management}

With regard to the management of the coastline we distinguish studies for characterizing emerged areas, from studies for underwater environments and finally for the interface between these two types of environments. This distinction is necessary because the sensors used, the specifications required for the data acquisition, and the data analysis methods are different in each environment. However, managers have to consider all these data together when managing these territories which are characterized by a wide range of different physical and human characteristics. 
The efficient management of specific coastal ecosystems requires knowledge on the spatial organization of vegetation and the understanding of underlying dynamics. In this context topographic LiDAR data can contribute to the characterization of the terrain (altitude, slope, geomorphology) as well as for the estimation of vegetation heights. In the salty marshes of the Mont Saint-Michel Bay, a statistical analysis that related plant species to factors such as elevation, morphology...helped to improve the vegetation mapping and confirmed that the coupling of LiDAR data with optical imagery was relevant (Bilodeau et al., 2010).

Mangroves are a very specific coastal area ecosystem, located in tropical regions within the intertidal zone in locations characterized by flat coasts or rivers mouths. For Guyanese mangroves, areas with difficult access, LiDAR data provided new types of information about topography and vegetation structure. It helped to identify two different colonization processes, which is a big step towards understanding the functioning and dynamics of these ecosystems. This is important because mangroves are threatened worldwide and they are also among the most productive ecosystems in biomass and play a crucial protective and regulatory coastal role (Proisy et al., 2007).

For new challenges in sustainable development of coastal areas and in management of natural hazards specific to these areas, bathymetric and topographic databases are today either insufficiently accurate or lacking. This fact led the IGN and the SHOM to develop the Litto3D program. The objective of this program is to establish, from both topographic and bathymetric airborne LiDAR surveys, a DTM at a one meter resolution, describing continuously the emerged surface areas with an elevation accuracy of about $30 \mathrm{~cm}$, the foreshore (part of the coastal area between high and low seas) and the nearshore (Flamanc and Le Roux, 2007).

\section{Research issues about LiDAR signal processing and accuracies}

In some early works, one application of LiDAR data in natural environment in France was to consider these data, i.e. canopy elevation data or terrain elevation data, as an irregularly sampled covariate to estimate terrain elevation, in addition to remote sensing optical or SAR images (Bourgine et al., 2004). The main challenge was to develop methods for radar and LiDAR data fusion (Baghdadi et al., 2005).

In the literature, another main issue concerns methodological developments to improve the accuracy of variables directly retrieved from the LiDAR signal. These activities may be grouped into two types of issues in connection with the two phases described above: 1) echo detection and backscattering signal processing to improve elevation accuracy 2) outlier points filtering and spatial interpolation, to define DTM or DSM.

\subsection{Research on LiDAR waveforms processing}

Part of the research work on LiDAR signal processing is dealing with information extraction from LiDAR waveforms (Durrieu, 2010; Mallet and Bretar, 2009), i.e. in a "full-waveform" data mode, which is the natural data mode for other LiDAR systems (e.g; satellite LiDARs, some atmospheric LiDARs... ). Environment characteristics are derived from waveform intensities and shapes (water column properties, benthos habitats mapping, biomass, terrain types, etc).

4.1.1. LiDAR waveform processing in hydrography and hydrology

Bathymetric or "green" LiDAR sensors are all full waveform and they usually emit in the NIR (1064 nm) and green $(532 \mathrm{~nm})$ wavelengths. The bathymetry, i.e. water depth is proportional to the time difference between the water surface and the water bottom positions identified in waveforms. One issue that plagues standard wavefom processing methods, which arevbased on mathematical function (e.g. Gaussian density, weibull density or triangle function) approximates, stems from the overlapping of surface and bottom waveform contributions (Figure 12) for very shallow waters (Lessaignoux et al., 2007). To overcome this problem a new waveform processing algorithm has been proposed by Allouis et al. (2010a). This algorithm combines the NIR and green waveforms and adds $41 \%$ of accurate bathymetry measurements in very shallow waters. Methods using Raman registered waveforms have also been tested (Allouis et al., 2010b).

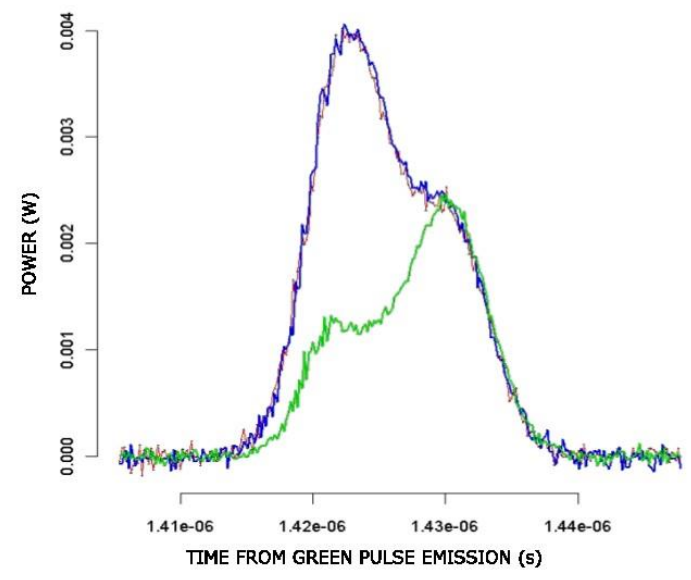

Figure 12 : Example of two green waveforms for a water depth of $0.8 \mathrm{~m}$ and two different water surface conditions (blue : with water surface roughness, green : without roughness) from Lessaignoux et al. (2007).

Following the studies of Populus et al. (2004), Ceccaldi (2011) recently processed green waveforms from 
the Hawkeye airborne sensor with a set of asymmetric mathematical functions in order to retrieve some benthos properties. Bottom intensities in waveforms depicted on Figure 13 are clearly related to sea bottom reflectance and benthos types: from vegetated and poorly reflective bottoms (green) for low intensities to sandy and highly reflective bottoms (dark and light brown) for high intensities.

In order to better explore waveform processing methods in various contexts, waveform simulation tools for hydrography and bathymetry have also been recently developed (Abdallah et al., 2012).

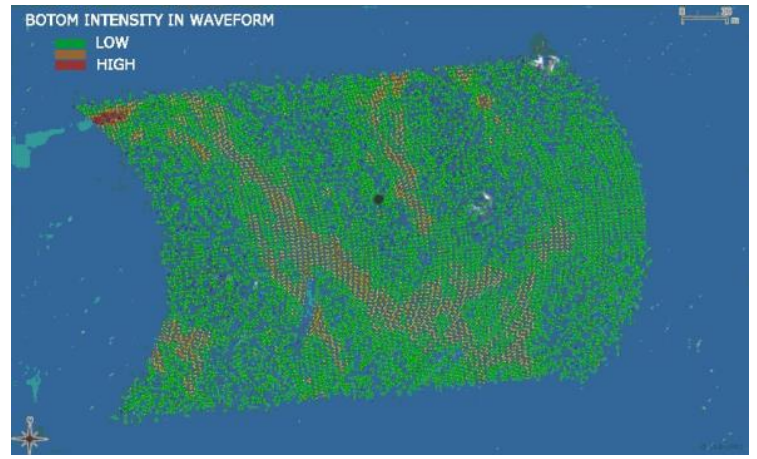

Figure 13 : Aerial photograph and bottom waveform intensities (colored points) from Hawkeye data in "Pays Bigouden" (\$ Ifremer) from Ceccaldi (2011).

\subsubsection{Full waveform analysis for forest applications}

Apart from the exploitation of the first and last echoes, and some possible intermediary echoes, full waveform analyses can be used to derive accurate information on the geometric and physical characteristics of the target (Durrieu, 2010).

Chauve et al. (2009) demonstrated that the fitting of certain number of parametric models, i.e., a sum of Gaussian or generalized Gaussian distributions, or a sum of log-normal functions can serve to extract echoes in a very efficient manner. Mallet et al. (2010) later showed that the use of a function grammar combining these different functions during the fittingprocess was even more efficient to improve the goodness of fit between the models and the waveforms. However the increase in goodness did not have repercussions on the following processing step, i.e. echo classification based on the parameters describing echo shapes. Thereby, modelling based on the summing of Gaussian distributions remains a very efficient and powerful method focused on the breakdown of small footprint LiDAR waveforms in forest areas (Chauve et al., 2009). In comparison with echoes supplied by service providers and based on the same data, the number of echoes identified using these approaches increased significantly by $+20 \%$ to $+100 \%$, in forest environments (Chauve et al., 2009; Mallet et al., 2010).

When waveforms are modelled as the sum of Gaussian functions, in addition to the position of the given target, we can avail of information on the intensity and width of the echo. This information can be used to better qualify the targets intercepted by the LiDAR beam, and has been used successfully in classification processes of LiDAR points in order to identify forest zones or trees in urban environments (Mallet et al., 2010).

Using a completely different analytical approach, Allouis et al. (2011a) aggregated waveforms tree by tree by summing all the waveforms included within each tree crown. The intensity profiles were then normalized by correcting the signal attenuation effect caused by the canopy. The information derived from the aggregated waveforms and the vegetation profiles obtained, in association with standard forest estimators - crown height, diameters - were used to improve estimations of above-ground biomass (Allouis et al., 2011a).

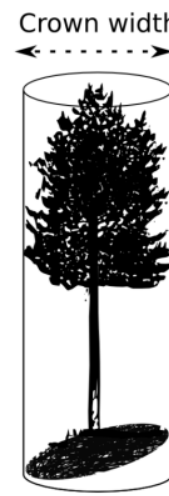

(a)
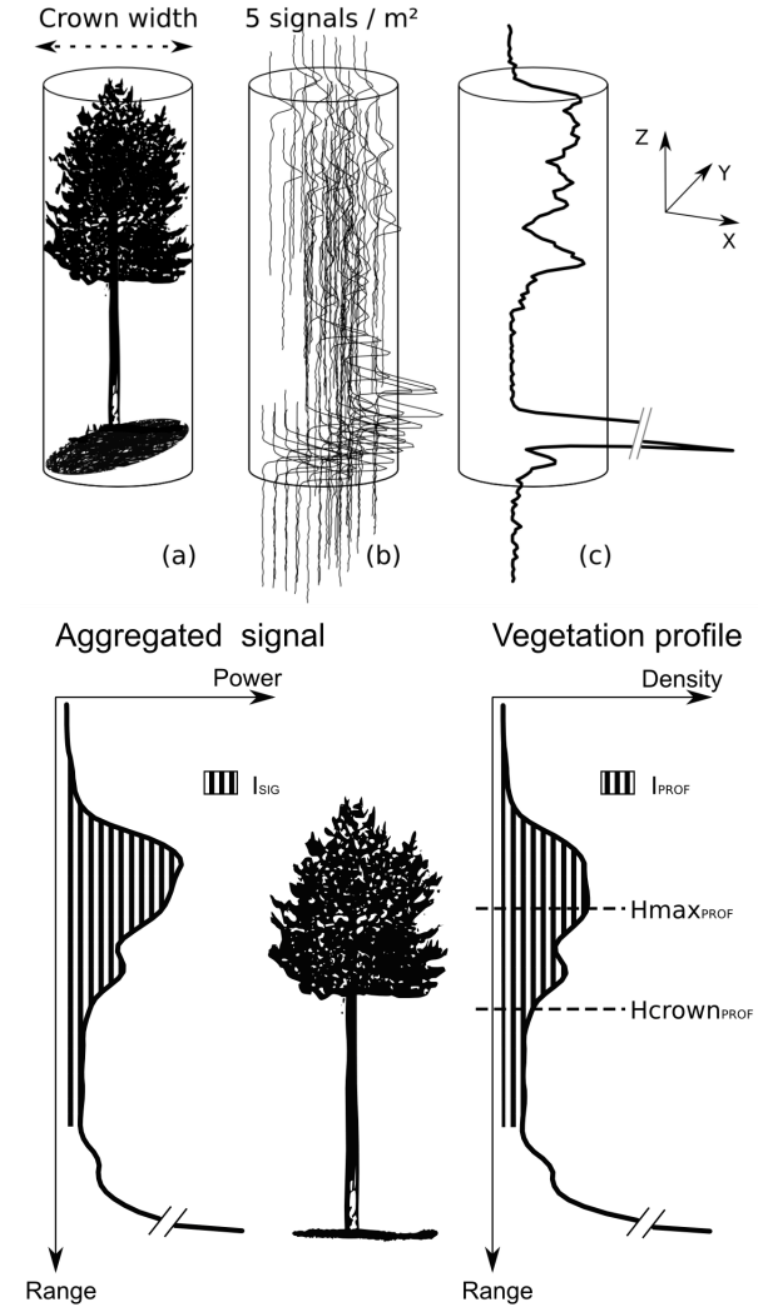

Figure 14 : Figure adapted from (Allouis et al., 2011a). A) Aggregation of small footprint waveforms at the tree level. B) Aggregated signal and vegetation profileof a tree. This vegetation profile is obtained by correcting the signal from occlusion effects. Information derived form both curves are used to improve biomass prediction equations-.

As for bathymetry, models are also developed to sim- 
ulate the waveforms backscattered by the vegetation. Simulation tools can help improve signal inversion methods and the retrieval of vegetation characteristic from real data. Such tools are also highly valuable in studies aiming to design new systems, e.g; spaceborne systems (see Section 5). They can be used to evaluate the impact of the wavelength, the proportion of multiple scattering that adds "noise" to the backscattered signal. . . (Dauzat et al., 2009). Several teams have started to develop modeling tools based on Monte Carlo ray tracing methods (Dauzat et al., 2009; Rubio et al., 2009; Ristorcelli et al., 2012). An ongoing project aims at comparing the several available models but, in such approaches, the main critical point is the vegetation model that is used. Further studies are planned to evaluate the impact on the simulated signal of changes in the vegetation model (e.g. trees represented using plant mock-up or ellipsoids filled with a turbid medium, etc).

\subsection{Researches on LiDAR point cloud processing}

We can classify these research works in two major groups:

-Prior to case studies presented in part 3, research that aims to refine methods to imrove DSM and DTM accuracy. The research focuses on the improvement of three specific phases: echo detection, classification or filtering of the "useful" points, and interpolation into DSM and DTM.

-Studies where the aim is to obtain the variables of interest directly from point cloud processing, without going through the raster step.

4.2.1. Point cloud quality and its impact on derivated products

The way in which the LiDAR point cloud is primarily derived from the signal will, of course, have a bearing on the quality of the results of point-cloud processing, e;g. the digital surface and terrain models that are computed.

How the position/location of echoes is computed represents a first step and can impact on accuracy. Indeed, several methods can be used to estimate the moment at which the LiDAR pulse was emitted and the moment at which the resulting echo was recorded by the sensor. According to the method used, slight differences in the resulting time of flight can be noticed (Durrieu, 2010). Methods based on simple signal thresholding willa prioribe less accurate than methods based on peak detection. For example Wagner et al. (2004), who studied the influence of echo detection methods on range errors for several targets, e.g. ground, branches, tree, roof, crops,..., report potential range errors ranging from $-21 \mathrm{~cm}$ to $+24 \mathrm{~cm}$ when a threshold is used to detect echoes and errors ranging from $-13 \mathrm{~cm}$ to +15 $\mathrm{cm}$ when a maxima detection approach is used. Indeed, in the case of a uniform surface (completely bare surface or water body....), the LiDAR pulse is reflected in an attenuated signal, that is generally accepted to be Gaussian. Attenuation stems from several factors such as the reflectance, the shape, the slope and the orientation of the target. The position given by a threshold will be sensitive to the level of attenuation and will be more or less closer from the peak. Other disturbances are linked to the multiple signal paths that generate drag on the return signal. This artificially increases the distance from the ground if we consider that its position is determined by the position of the last point showing intensity greater than the level of noise.

Moreover, certain systems used to produce a ringing effect which is a false parasitic echo linked to a detector fault, and recorded following a highly intense echo generated by highly reflective targets in the wavelength used by the system (Durrieu, 2010). When the characteristics of these parasitic echoes are taken into account their impacts can be suppressed (Chauve et al., 2009). If this problem is now resolved for recent systems, it can still be found by users who need to process or reprocess archive data.

The sensor type and its ability to record one or more echoes or the complete shape of the backscatter signal will also have a bearing on the quality of surface models obtained. In mono-echo mode, if only the last echo is recorded, the heights of surface models in a forest environment will certainly be under-estimated. Alternatively, if only the first echo is recorded, DSM quality will be better but the densiity of ground points will be lower and DTM quality will suffer. Multi-echo or full waveform systems should thus be favoured. However, if an industrial single-echo system is used, we cannot know how the signal was processed in order to generate echoes. Thus, the end-user does not have access to all the information required to accurately assess the quality of date produced during airborne LiDAR acquisition. (Durrieu, 2010).

\subsubsection{Ground point classification and filtering}

The classification and filtering of LiDAR returns into ground and over-ground returns (i.e., infrastructure and vegetation) is a critical step towards the generation of accurate DTM., which has been widely addressed in literature. The TIN iterative approach (Axelsson, 2000), used in Panissod et al. (2010) can be considered as the current reference among existing filtering approaches. The method involves progressive densification of a triangle network. The first Triangulated Irregular Network (TIN) is built using a subset of local minima. Points are then added to the triangle network according to geometric criteria (distances, angles). Panissod et al. (2010) proposed different settings using the TIN-iterative approach and illustrate the influence of initial point density on the restitution quality of the surface. In a recent review paper, Meng et al. (2010) pointed out that current ground 
filters are mostly based on four ground characteristics, namely: lowest feature in a specific area, a ground slope threshold, ground surface, an elevation difference threshold, and smoothness. Most algorithms use geometric rules based on the assumption that the ground is less sloped and has a smoother surface than the DSM surface including aboveground objects. This assumption is no more valid in areas characterized by complex topography (e.g. badlands) or in forested and relief environments where the geometrical characteristics of the ground surface can present similarities with those of aboveground elements (Vega et al., 2012). Furthermore, optimizing the algorithm parameters to process large and topographically complex areas, where ground morphology can drastically vary from one point to another one, remains challenging. To overcome these difficulties, Bretar et al. (2007, 2009) proposed a two step filtering process. The first step consists in the computation of an initial surface using a predictive Kalman filter that aims at providing a robust surface containing low spatial frequencies of the terrain (main slopes). The second step consists in refining this surface using a Markovian regularisation that can integrate micro reliefs. More recently, Vega et al. (2012) proposed a virtual deforestation algorithm that iteratively detects and filters objects above the ground. The performance of the algorithm was compared to 9 other filtering methods on some ISPRS sites with relief and vegetation. The algorithm performed very well and even better on one site than the TIN iterative approach (Vega et al., 2012). This new algorithm has shown good potential for the processing of high density point clouds and for the computing of accurate DTMs under forest covers in areas characterized by a complex morphology (minimal and maximal errors of $-0.63 \mathrm{~m}$ and $0.28 \mathrm{~m}$, and a RMSE of $0.14 \mathrm{~m}$ ).

\subsubsection{Surface interpolation}

Point density is an important factor that can have a bearing on the quality of surface models. The density and the distribution of the points retained for the computation of a DTM and a DSM are directly dependent of LiDAR point density and must be optimized by taking into account the relative geometric characteristics of above ground and surface objects. Vega et al. (2012) recall that, as demonstrated in several studies, DTM accuracy depends on (1) sensor characteristics and flight parameters, (2) the Earth's surface characteristics (i.e. topography and land cover), and (3) the methods used to produce the DTM., e.g. resolution, filtering and interpolation methods. In rough terrains with vegetation cover, factors that cause imprecision tend to accumulate (footprint width, terrain slope, multiple emissions) make these environments especially difficult to work on.

Concerning DSM, after a filtering step aiming at suppressing outliers, we retain the topmost point in a cell of a given size to compute the numerical model of the surface. The missing variables are computed by interpolation. The accuracy will depend on related geometrical considerations: 1) the LiDAR signal and the width of the LiDAR footprint used and the density of measurements, 2) target characteristics that depends on the tree species studied: round or pointed crown, degree of canopy closure, density and smoothness of tree stand as well as the slope of the natural terrain.

For example, the top of a pointed crown in a large footprint will not return enough energy to be identified in the backscattered signal. In addition, the probability of not successfully sampling the topmost points of trees increases as the density of LiDAR measurements decreases. Thus, we can expect a systematic underestimation of total tree heights when using a LiDAR. This underestimation is however limited and the LiDAR remains a technique that is adapted to the measurement of heights of forest stands (Chauve et al., 2009; Bock et al., 2011; Allouis et al., 2011a).

4.2.4. Using LiDAR point cloud to derive useful variables

In certain types of applications, raster data such as DTM or CHM are too smooth, and some researchers prefer to work directly on LiDAR point clouds. These approaches are a priori more relevant for environments of variable topography or to improve the description of forest environments.

In the latter case, cloud points are used to improve the estimation of inventory parameters - heights, trunk diameters, volumes and biomass - or to describe different forest strata. A first step can take the form of a statistical analysis of point distribution according to height, often expressed in quantile form. We know that the use of certain percentiles in regression models that link forest parameters and LiDAR metrics does indeed improve these models. Several authors have used these techniques, certain at the individual tree level (Allouis et al., 2011a) and others at the forest plot scale (Monnet, 2011). The latter chose to integrate additional variables into their models, e.g., entropy and criteria measuring the heterogeneity of the heights of numerical models of the plot canopy.

Ferraz et al. (2012) have used a statistical approach based on the mean shift algorithm, to segment the point cloud and to individually represent each plant in the form of an envelope for the different vegetation, i.e, ground vegetation, overstory and understory. Such an approach may be used as a basis for the characterisation of total biomass including shrubs that is required for fuel mapping, forest fire management, improved forest inventory and carbon balance.

\section{Instrument Development in France}

Until now, most applications and research efforts have, until now, used data acquired by industrial 
(topographical) or semi-industrial LiDAR systems (bathymetric) which have been developed abroad and fitted on board planes and helicopters. Today, we can observe some new development initiatives for airborne systems designed to meet very specific needs at both research and application levels. For instance, an airborne LiDAR prototype fitted to an ultra light aircraft (ULA) was developed by the CEA/LSCE and its potential for forest stand characterization was assessed (Cuesta et al., 2010a,b; Allouis et al., 2011a). After validation of the first version, an improved version of this prototype was recently developed (Chazette et al., 2011; Bouvier et al., 2011). The aim now is to develop new capacities for this prototype so that it can reach towards a muli-purpose atmosphere-vegetation LiDAR that would be made available to the scientific community and which would provide simultaneously information on these two environments. This would allow a better understanding of the phenomena operating at the atmosphere/vegetation interface.

Another trend is the developement of LiDAR systems to be embarked on ULAs and drones. For instance, the Avion Jaune company (http://www.lavionjaune.fr/) plans to develop such a system and aims to provide users with LiDAR surveys in a more cost effective way than with standard airborne data This type of data meets the requirements of certain users who need LiDAR survey data for small surface areas for which using in a plane would be cost prohibitive.

Finally, the transfer of LiDAR technology to spatial solutions has been the subject of several projects illustrating the current dynamism of the French scientific community in this area. The American Icesat satellite, which operated from 2003 to 2009, confirmed that this technology had reached a degree of maturity that was sufficiently advanced to envisage the development of space missions dedicated to the study of continental surfaces. To this day, three projects with French principal investigators have been submitted in response to a call for proposal by the ESA:

-The Z-Earth and LEAF projects, were submitted in response to the 8th Earth Explorer call for proposal from the ESA (the European Space Agency) in 2010, with the support of the CNES and Astrium. Z-Earth is a system designed to acquire information on surface topography at very high spatial resolutions, in a repetitive manner and at a global scale. Its primary objective is to meet the information needs of the scientific community in the field of natural hazards. The system is based on the coupling of a stereo surface imager and a LiDAR (Dewez, 2012). The primary objective of LEAF, which couples a large footprint LiDAR with a highresolution imager, is to compute forest biomass on a global scale (Durrieu, 2010). These projects were not selected by the ESA but are still under study with the support of the CNES.

-GRAIL - "Green and blue carbon budget investigation by LiDAR" (PI P. Flamant / LMD- The Laboratory of Dynamic Meteorology) which was also submitted to the ESA in response to a call for ideas for ISS Experiments relevant to the study of Global Climate Change in November 2011. Its objective is the estimation of blue and green carbon. Partnerships are possible with other projects submitted by other scientific teams, JAXA (the Japan Aerospace Exploration Agency) and the NASA (the American National Aeronautical and Space Agency).

\section{Conclusions and outlooks}

This paper takes the form of a review of research initiatives in France that focus on the application of LiDARs in natural environments in order to measure soil surface relief and discontinuities, vegetation structure, immersed surface relief, etc. Airborne LiDAR appears to be a natural environment survey system that is mature enough in many areas, to really assist the mapping and monitoring of various environments (waterbodies, catchments, forests, ecosystems, infrastructures, etc). The development of LiDAR based studies can be explained by several LiDAR data features: high planimetric and altimetric accuracies, high spatial resolution, canopy penetration capabilities and cost effectiveness.

Two types of research initiatives have been taken in the French airborne LiDAR community that work in natural environments: a first 'dowstream' type, which is the most common, is currently assessing the added value of LiDAR DTM, DSM and CHM in environmental disciplines and a more 'upstream type' working on signal processing, and striving to improve the accuracy of variables retrieved from LiDAR signals or raw data.

New sensor development (new wavelengths, new photodiodes technologies), progress in storage capacities and processing methods are arriving almost continuously, thereby providing new potential applications. Regarding the French LiDAR community, some innovative LiDAR systems, such as oblique shooting systems for mapping and monitoring of cliffs, light systems that can be fitted onboard light aircrafts or drones, with features that can differ from industrial systems (e.g. wavelength, footprint size...) are tested. In addition space LiDAR missions, are also being proposed by international teams leaded by a French partner. In environmental sciences, LiDAR (ground-based (Terrestrial Laser Scanner or TLS), airborne, spaceborne) is already seen as both an essential and promising technology. While the LiDAR community was not clearly identified and not very active in France ten years ago. This community has now became very active and dynamic in the development of research on LiDAR in order to better under- 
stand the complexity of natural environments, to develop knowledge about these environments and to facilitate its management. The national seminars dedicated to LiDAR (see proceedings in the issues 186,191 and 192 of the RFPT, the French Journal of Photogrammetry and Remote Sensing), favored the exchanges between several research communities and contributed to the current dynamic of the research community using LiDAR for natural environments.

\section{References}

Abdallah, H., Bailly, J., Baghdadi, N., Lemarquand, N. , 2011. Improving the assessment of ICESat water altimetry accuracy accounting for autocorrelation. ISPRS Journal of Photogrammetry and Remote Sensing 66(6), 833-844.

Abdallah, H., Bailly, J., Baghdadi, N., Pastol, Y., Fabre, F, 2012. WA-LiD: a LiDAR waveform simulator for Waters. IEEE Geosciences and Remote Sensing Letters 9, 744-748.

Allouis, T., Bailly, J.S., Pastol, Y., Le Roux, C., 2010. Utilisation conjointe de trains d'ondes LiDAR vert et infrarouge pour la bathymétrie des eaux de très faibles profondeurs. RFPT 192 (2010), 52-61.

Allouis, T., Bailly, J., Pastol, Y., LeRoux, C., 2010. Comparison of LiDAR waveform processing methods for very shallow water bathymetry using Raman, near-infrared and green signals. Earth Surface Processes and Landforms 35(6), 640-650.

Allouis, T., Durrieu, S., Chazette, P., Bailly, J.S., Cuesta J., Véga, C., Flamant, P., Couteron, P., 2011. Potential of an ultraviolet, medium-footprint LiDAR prototype for retrieving forest structure. ISPRS Journal of Photogrammetry and Remote Sensing 66(6), S92-S102.

Allouis, T., Durrieu, S., Véga,, C., Couteron, P., 2011. Exploiting full-waveform LiDAR signals to estimate timber volume and above-ground biomass of individual trees. In: IEEE International Geoscience and Remote Sensing Symposium (IGARSS). IEEE, Vancouver, Canada, 24-29 July 2012, pp. $1251-1254$

Axelsson, P., 2000. DEM Generation from laser scanner data using adaptive TIN models. International Archives of the Photogrammetry Remote Sensing and Spatial Information Sciences 33(Part B4/1), 110-117.

Baghdadi, N., Cavelier, S., Chiles, J.P., Bourgine, B., Toutin, T., King, C., Daniels, Ph., Perrin, J., Truffert, C., 2005. Merging of airborne elevation data and RADARSAT data to develop a Digital Elevation Model. International Journal of Remote Sensing 26(1), 139-163.

Bailly, J., Lagacherie, P., Millier, C., Puech, C., Kosuth, P., 2008. Agrarian landscapes linear features detection from LiDAR: application to artificial drainage networks. International Journal of Remote Sensing 29(12), 3489-3508.

Bailly, J.S., LeCoarer, Y., Languille, P., Stigermark, C., Allouis, T., 2010. Geostatistical estimation of bathymetric LiDAR errors on rivers. Earth Surface Processes and Landforms 35(10), $1199-1210$

Bailly, J.S., Kinzel, P., Allouis, T., Feurer, D., LeCoarer, Y.Carbonneau, P., Piégay, H., ed., 2012. Fluvial Remote Sensing for Science and Management, Wiley Ed., chapter Airborne LiDAR methods applied to riverine environments, in press.

Balouin, Y., Heurtefeux, H., 2007. Utilisation de la technologie LiDAR bathymétrique pour le suivi du littoral: retours d'expériences sur le littoral méditerranéen. RFPT 186 (20072), 74-80
Barbier, N., Proisy, C., Véga, C., Sabatier, D., Couteron, P., 2011. Bidirectional texture function of high resolution optical images of tropical forest: An approach using LiDAR hillshade simulations. Remote Sensing of Environment 115(1): 167179.

Berthier, E., 2007, Dynamics and mass balance of mountain glaciers (Alps, Iceland, Himalaya). Contribution of satellite imagery [Dynamique et bilan de masse des glaciers de montagne (Alpes, Islande, Himalaya). Houille Blanche 2, 116121.

Berthier, E., Vincent, C., 2012. Relative contribution of surface mass balance and ice flux changes to the accelerated thinning of the Mer-de-Glace (Alps) over 1979-2008. Journal of Glaciology 58(209), 501-512.

Bilodeau, C., Deroin, J.P., Radureau, A., Cohen, M., 2010. Estimation du potentiel des données LiDAR multiécho pour l'étude de la végétation des marais salés : étude du biais des données LiDAR acquises au-dessus de la baie du Mont Saint Michel et recherche d'une méthode de correction. RFPT 192(2010), 18-28

Bilodeau, C., 2010, Apports du LiDAR à l'étude de la végétation des marais salés de la baie du Mont-Saint-Michel, $\mathrm{PhD}$ thesis, Université Paris Est, France, 209 p.

Bock, J., Renaud, J.P., Dez, G., Martins, F., Leroy, M., Dambrine, E., Dupouey, J.L. 2011. LiDAR, powerful tool to map the height of the forest settlements- Le LiDAR, outil performant pour cartographier la hauteur des peuplements forestiers. RenDez-Vous Techniques 32, 39-44.

Bock, J., Dupouey, J.L., Dambrine, E., Georges-Leroy, M. 2008. Archaeological structures and stands in the state forest of Haye analysed by airborne laser. Les structures archéologiques et les peuplements de la foret domaniale de Haye analyses par laser aéroporté. RenDez-Vous Techniques 20, 15-18.

Bock, J., Dambrine, E., Dez, G., Dupouey, J.-L., Georges-Leroy, M., Jolly, A., Martins, V., Renaud J.-P., 2009. Towards site index mapping in deciduous stands using multi-echo LIDAR data. In: Proceedings of the workshop Space and Time, Quebec City, Canada, 17-19 May 2009.

Bourgine, B., Baghdadi, N., Hosford, S., Daniels, P., 2004. Generation of a ground-level DEM in a dense equatorial forest zone by merging airborne laser data and a top-of-canopy DEM. Canadian Journal of Remote Sensing 30(6), 913-926.

Bretar, F., Mallet, C., Flamanc, D., David, N., 2007. Traitement des données LiDAR: vers une solution globale. RFPT 186(2007-2), 36-47.

Bretar, F., Chauve, A., Bailly, J., Mallet, C., Jacome, A., 2009. Terrain surfaces and 3D landcover classification from small footprint full-waveform LiDAR data: Application to badlands. Hydrology and Earth Sciences Systems 13(8), 1531-1544.

Bouvier, M., Allouis, T., Durrieu, S., Chazette, P. 2011. Estimating forest biomass from medium to large footprint LiDAR data. In: Geophysical Research Abstracts, vol. 13. EGU General Assembly 2011, Vienna, Austria, 4-8 April 2011.

Ceccaldi, M., 2011. Utilisation du LiDAR bathymétrique à retour d'onde complète pour la classification en zone côtière, Université Marne-la-Vallée, Master Thesis.

Ciampalini, R., Follain, S., Le Bissonnais, Y., 2012. Landsoil: a model for the analysis of erosion impact on agricultural landscape evolution. Geomorphology, in press.

Clement A., Mériaux P., 2007. La télédétection LiDAR : projet Flip-map et derniers développements de l'utilisation de méthodes à haut rendement pour la reconnaissance de digues fluviales françaises. RFPT 186(2007-2), 92-95.

Chauve, A., Vega, C., Durrieu, S., Bretar, F., Allouis, T., PierrotDeseilligny, M., Puech, W., 2009. Advanced full-waveform LiDAR data echo detection: Assessing quality of derived terrain 
and tree height models in an Alpine coniferous forest. International Journal of Remote Sensing 30(19), 5211-5228.

Chazette P., Soudani K., Royer P., Sanak J., Lardier M., Allouis T., Bouvier M., Durrieu, S., 2011. Forest canopy attributes derived from airborne LiDAR above the Barbeau/Fontainebleau forest In: Geophysical Research Abstracts, Vol. 13. EGU General Assembly 2011, Vienna, Austria, 4-8 April 2011.

Couteron, P., Pélissier, R., Nicolini, E., Paget, D., 2005. Predicting tropical forest stand structure parameters from Fourier transform of very high resolution canopy images. Journal of Applied Ecology 42(6), 1121-1128.

Cuesta, J., Chazette P., Allouis T., Sanak, J., Genau, P., Flamant, P.H., Durrieu, S., Flamant, C., 2010a. La canopée forestière vue par un LiDAR ultra violet aéroporté de nouvelle génération. RFPT 191(2010), 19-27.

Cuesta, J., Chazette, P., Allouis, T., Flamant, P.H., Durrieu, S., Sanak, J., Genau, P., Guyon, D., Loustau, D., Flamant, C., 2010b. Observing the forest canopy with a new ultra-violet compact airborne LiDAR. Sensors 10(8), 7386-7403.

Dauzat, J., Stefas, M., Chauve, A., Caraglio, Y., Durrieu, S., 2009. Simulation de mesures LiDAR par tracé de rayons sur des plantes virtuelles. In: SFPT workshop 'Techniques Laser pour l'étude des environnements naturels et urbains', SFPT, ESGT, Le Mans, France, 20-21 January 2009.

Dewez, T., Costeraste, J., 2012. Global dynamic topography: geoscience communities requirements. In: Geophysical Research Abstracts, Vol. 13. EGU General Assembly 2011, Vienna, Austria, 4-8 April 2011.

Dorren, L., Berger F., Maier B., 2007. Cartographier la structure forestière avec un système LiDAR aéroporté en terrain montagnard. RFPT 186(2007-2), 54-59.

Dupuy, S., Lainé, G., Tassin, J., Sarrailh, J.M., 2011. Classification et cartographie des espaces boisés de Mayotte : combinaison de données LiDAR et multispectrales. In : 22ème Festival International de Géographie (FIG) : L'Afrique plurielle, paradoxes et ambitions. Saint-Dié-des-Vosges, France, 6-9 October 2011.

Durrieu S., 2007. Le LiDAR à retour d'onde complet, nature de l'information enregistrée et perspectives d'utilisations. RFPT 186(2007-2), 15-35.

Durrieu, S., 2010. Design of a European space borne LiDAR System for vegetation mapping- LEAF: LiDAR for Earth And Forests. In: Silvilaser. Freiburg, Germany, 14-17 September 2010.

Elineau, S., Duperreti, A., Mallet, P., Caspar, R., 2010. Le Havre : une ville côtière soumise aux submerssions marines et aux isntabilités de falaises littorales. In: Actes des journées Impacts du changement climatique sur les risques côtiers. BRGM, 15-16 November 2010, Orléans-France, pp. 171174

Ferraz, A., Bretar, F., Jacquemoud, S., Gonçalves, G, Pereira, L., Tomé, M., Soares, P., 2012. 3D mapping of a multi-layered mediterranean forest using ALS data. Remote Sensing of Environment 121, 210-223.

Flamanc, D., Le Roux, C., 2007. Litto3D pour mieux connaître le littoral. R\&E 7, 28-29.

Flamant, P.H., 2005. Atmospheric and meteorological LiDAR: from pioneers to space applications. Comptes Rendus Physique 6(8), 864-875.

Friedt, J.-M., Tolle, F., Bernard, E., Griselin, M., Laffly, D., Marlin, C., 2012. Assessing the relevance of digital elevation models to evaluate glacier mass balance: Application to Austre Lovénbreen (Spitsbergen, $79^{\circ} \mathrm{N}$ ). Polar Record 48(1), 2-10.

Heggy, E., Sedze, M., Bretar, F., Jacquemoud, S., Rosen, P.A., Wada, K., Staudacher, T., 2010. Coupling polarimetric Lband InSAR and airborne LiDAR to characterize the geomorphological deformations in the Piton de la Fournaise vol- cano. In: IEEE International Geoscience and Remote Sensing Symposium (IGARSS). IEEE, Honolulu, HA, USA, 25-30 July 2010, pp. 1911-1913.

Jacome, A., 2009. Modèle Numérique de Terrain à très haute résolution spatiale pour la représentation $3 \mathrm{D}$ de ravines d'érosion en montagne. PhD thesis Agro-Paris-Tech Paris.

Jang, J.J., Thevand, A., Viau, A., Gond, V., 2007. Estimation des différents stades de développement d'une jeune mangrove par utilisation de LiDAR aéroporté. RFPT 186(2007-2), 6067.

Kreis, N., Juillet, S., Villemin, T., Perrette, Y., Delannoy, J.J., 2010. Valorisation de levers lasers aéroportés pour la gestion intégrée du risque d'inondation, quelques exemples dans le département du Haut Rhin. RFPT 192(2010), 44-49.

Lessaignoux, F., Bailly, J.S., Allouis, T., Feurer, D., 2007. Epaisseur d'eau minimale mesurable en rivière sur fronts d'onde LiDAR simulés. RFPT 186(2007-2), 48-53.

Mallet, C., Bretar, F., 2009. Full-Waveform Topographic LiDAR: State-of-the-Art. ISPRS Journal of Photogrammetry and Remote Sensing 64(1), 1-16.

Mallet, C., Lafarge, F., Roux, M., Soergel, U., Bretar, F., Heipke, C., 2010. A Marked Point Process for Modeling LiDAR Waveforms. IEEE Transactions on Image Processing 19(12), 3204-3221.

Mei, C., Durrieu, S., 2004. Tree Crown Delineation from Digital Elevation Models and High Resolution Imagery. International Archives of Photogrammetry, Remote Sensing and Spatial Information Sciences 36(Part8/W2), 218-223.

Meng, X., Currit, N., Zhao, K., 2010. Ground Filtering Algorithms for Airborne LiDAR Data: A Review of Critical Issue. Remote Sensing 2, 833-860.

MAAPAR, 2011. L'utilisation du territoire en 2010. Ministère de l'agriculture, de l'alimentation, de la pêche, de la ruralité et de l'aménagement du territoire, Agreste Primeur, N ${ }^{\circ} 260$, Avril 2011

Monnet, J.-M. 2011. Caractérisation des forêts de montagne par scanner laser aéroporté: Estimation de paramètres de peuplement par régression SVM et apprentissage non supervisé pour la détection de sommets. Ph.D. thesis Université de Grenoble, France.

Panissod, F., Bailly, J.S., Durrieu S., Jacome A., Mathys, N., Cavalli, M., Puech C, 2010. Quantification de modèles numériques de terrain LiDAR pour 1 'étude de l'érosion : application aux badlands de Draix. RFPT 192(2010), 50-57.

Pedreros, R., Lecacheux, S., Delvallée, E., Balouin, Y., Garcin, M., Krien, Y., Le Cozannet, G., Poisson, B. , Thiebot J., 2010. Mise en place d'une approche multi-modèles pour évaluer l'exposition du littoral languedocien aux submersions marines dans un contexte de changement climatique (Projet MISEEVA). In: Actes des journées Impacts du changement climatique sur les risques côtiers. BRGM, 15-16 November 2010, Orléans-France, pp.71-74.

Pénard, L., Morel, M., 2012, Automatic detection of gravel bars in a river channel from airborne LiDAR-derived DTM. In: 10th International Conference on Hydroinformatics. Hamburg, Germany, 14-18 July 2012.

Populus, J., Laurentin, A., Rollet, C., Vasquez, M., Guillaumont, B., Bonnot, C., 2004. Surveying coastal zone topography with airborne remote sensing for benthos mapping. Journal of Remote Sensing and Photogrammetry 3(1), 105-117.

Proisy, C., Couteron, P., Fromard, F., Pélissier, R. 2007. Mangroves dynamics from FOTO of IKONOS images and LiDAR data. In: VIII workshop ECOLAB, Macapa, Brasil, 6-12 AUgust 2007.

Proisy, C., Gratiot, N., Anthony, E. J., Gardel, A., Fromard, F., Heuret, P. 2009. Mud bank colonization by opportunistic mangroves: A case study from French Guiana using LiDAR data 
Continental Shelf Research 29, 632-641.

Sarrazin, B., 2012. MNT et observations multi locales du réseau de drainage d'un petit bassin versant rural dans une perspective d'aide à la modélisation spatialisée. $\mathrm{PhD}$ thesis Université de Grenoble, 265p.

Ristorcelli, T., Hamoir, D., Briottet, X., Cazanave, G., Petit, D., Gastellu-Etchegorry, J.-P., 2012. Modelling of full-waveform, 3D laser imaging for vegetation characterisation and foliage penetration. In: OPTRO 2012. SPIE, 8-10 February 2012, Paris, France.

Rubio, J., Grau, E., Gastellu-Etchegorry, J.-P., Sun, G, Ranson, K.J., 2009. LiDAR modeling with the 3d DART model. In: American Geophysical Union, San Francisco, CA, USA, 14-18 December 2009.

Sittler, B., Koupaliantz, L. 2007. Premières applications de la technique du LiDAR appliquée à l'étude des sites patrimoniaux. Les exemples allemands et alsaciens. RFPT 186(20072), 68-73.

Thommeret, N., Bailly, J. S., Puech, C., 2011. Extraction of thalweg networks from DTMs: application to badlands. Hydrological Earth System Sciences, 14, 1527-1536.

Véga, C., Durrieu, S., 2011. Multi-level filtering segmentation to measure individual tree parameters based on LiDAR data: Application to a mountainous forest with heterogeneous stands. International Journal of Applied Earth Observation and Geoinformation 13(4), 646-656.
Véga, C., Durrieu, S., Morel, J., Allouis, T., 2012. A sequential iterative dual-filter for LiDAR terrain modelling optimized for complex forested environments. Computers\&Geosciences, In Press.

Vennetier, N., Mériaux, P., Busset, F., Félix, H., Lacombe, S., 2010. Apport de la télédétection LiDAR aéroportée haute définition pour la caractérisation de la végétation des digues. RFPT 191(2010), 36-41.

Vincent, G., Wiessenbacher, E., Sabatier, D., Blanc, L., Proisy, C., Couteron, P., 2010. Détection des variations de structure de peuplements en forêt dense tropicale humide par LiDAR aéroporté. RFPT 191(2010), 42-51.

Wagner, W., Ullrich, A., Melzer, T., Briese, C., Kraus, K., 2004. From Single-pulse to Full-waveform Airborne Laser Scanners: Potential and Practical Challenges. International Archives of the Photogrammetry Remote Sensing and Spatial Information Sciences 35(Part B3), 110-117.

Zhou, J., Proisy, C., Descombes, X., Hedhli, I., Barbier, N., Zerubia, J., Gastellu-Etchegorry, J.P., Couteron, P., 2010. Tree crown detection in high resolution optical and LiDAR images of tropical forest. Tree crown detection in high resolution optical and LiDAR images of tropical forest XII(7824). 